\title{
Novel Therapeutic Paradigms to Treat Hemodialysis Access Dysfunction
}

\author{
Lalathaksha Kumbar ${ }^{*}, 1$, Jian $\mathrm{Li}^{1}$, Hafeez Alsmaan ${ }^{1}$ and Anatole Besarab ${ }^{2}$ \\ ${ }^{I}$ Division of Nephrology and Hypertension, Henry Ford Hospital, Detroit MI, USA; Wayne State School of Medicine, \\ Detroit MI, USA \\ ${ }^{2}$ Division of Nephrology, Stanford University, Stanford, California, USA
}

\begin{abstract}
Vascular access dysfunction continues to be a major factor contributor to the morbidity and mortality of hemodialysis patient. Percutaneous intervention has been the central therapeutic modality used to treat dialysis vascular access dysfunction with limited success. Vascular biology research has shed considerable light on the pathophysiologic processes that lead to the development of neointimal hyperplasia, the culprit lesion for vascular access dysfunction, suggesting possible newer novel therapeutic interventions. In this review we discuss; (1) recent advances in the utilization of image based predictive medicine in improving access type selection prior to access creation; (2) current and promising treatment modalities including brachytherapy, gene therapy and pharmacotherapy for prevention of neointimal hyperplasia; (3) alternate imaging modalities during percutaneous endovascular interventions. Though novel therapeutic interventions are evolving, robust clinical studies to identify optimal therapeutic method are needed. A combination of evidenced based interventions from pre access creation up until final abandonment of vascular access is worthy of exploration.
\end{abstract}

Keywords: Angioplasty balloons, antiproliferative agents, arteriovenous fistula, predictive medicine, ultrasound guided angioplasty.

\section{INTRODUCTION}

Vascular access (VA), often referred to as the achilles heel of hemodialysis (HD), is one of the weakest links in the care of an HD patient. VA dysfunction contributes to the morbidity and mortality of HD patients at a significant financial cost. Among the available VA options, catheters are least and functional arteriovenous fistula (AVF) are most preferred, with arteriovenous graft (AVG) residing in the middle. Etiology for VA dysfunction among AVF and AVG is mainly attributed to development of neointimal hyperplasia (NIH) [1]. Today, after more than 50 years since the introduction of AVF, AVG and percutaneous transluminal angioplasty (PTA) balloons for treatment of stenosis, the effective treatment of VA dysfunction remains elusive [2]. Recent advances in our understanding of the pathophysiology of NIH and of fluid dynamics, combined with advances in endovascular devices are leading to the evolution of newer therapies. The aim of this review is to identify recent advances in novel therapeutic modalities.

\section{ADVANCES IN PRE-OPERATIVE VASCULAR MAPPING}

Evaluation of the vasculature prior to access construction has moved beyond the simple physical examination alone to include Doppler ultrasound (US) studies and or angiography to delineate the targeted access vasculature. This has occurred in part from the aging of the population in whom a

*Address correspondence to this author at the Division of Nephrology and Hypertension, Henry Ford Hospital, CFP 507, 2799 West Grand Boulevard, Detroit, MI 48202, USA; Tel: 313-916-2711; E-mail: 1kumbar1@hfhs.org greater burden of arterial disease at potential sites of construction might be expected and from the recent documentation, that the veins themselves in advanced CKD are horribly diseased [3]. Use of US in conjunction with physical examination has improved fistula anatomic patency and functional patency $[4,5]$. However, despite the widespread use of pre-operative vascular mapping, the fistula maturation can still be unpredictable and disparities in patients over 65 years, females and in forearm location persist [6].

\section{Predictive Medicine in Vascular Access Care}

Predictive medicine, a relatively new discipline uses computational tools with patient specific data in a model based approach to provide additional information for the access surgeon. Pulse wave propagation data incorporating patient specific parameters during duplex ultrasound examination (US) along with arterial data from the published literature can be used to make decisions. Bode et al. tested a predictive model based on such pulse wave propagation to predict post operative blood flow a major determinant of maturation and patency in AVF [7]. AVF surgical site was assumed to be within $5 \mathrm{~cm}$ from the elbow or wrist joints and the angle of anastomosis at $45^{\circ}$. For each patient, three AVF configurations (radiocephalic fistula, brachiocephalic fistula and brachiobasilic transposed fistula) were considered. Model recommended the AVF option based on the predicted flow between $400 \mathrm{ml} / \mathrm{min}$ to $1500 \mathrm{ml} / \mathrm{min}$. The suggested configuration was then compared with the surgeon's choice. Preoperative arterial mean blood flows were measured by Magnetic Resonance and post operative flows were 
measured using US after one week post fistula creation. Twenty three out of 25 patients had clinically measured flows post fistula creation. Predicted flow overlapped with measured blood flow at one week post operation in about $70 \%(16 / 23)$ patients and had an agreement of $76 \%$ with the choice of the surgeon. Though this study suffers from the small sample, incomplete patient specific parameters, different flow measurement techniques and short term flow prediction, it is an important step in developing an adjuvant tool in the preoperative workup of patients receiving access surgeries.

Following-up on the work of Bode, a more recent study uses non contrast enhanced magnetic resonance angiography (NCE-MRA) to provide arterial characteristics and semi quantitative venous characteristics [8]. This study from Netherlands aimed to assess the effect of geometric input on prediction of blood flow in vascular access using a generic circulation model with individualization limited to arm geometry (arterial diameters by NCE-MRA and venous parameters by US) and arterial flow using duplex ultrasound. At the end of the study, data on 21 out of 25 subjects was available for analysis; $70 \%(15 / 21)$ had an overlap of predicted and measured blood flows. Some of the weaknesses from the Bode study continue to persist including use of ultrasound method for flow measurements and dissimilar methods to measure arterial and venous parameters. Clinical use is likely to be limited due to logistics of acquiring the preoperative data and the inhibitory cost of magnetic resonance angiography.

The aim of these predictive modeling studies is to develop a clinical tool to provide patient specific vascular access advice prior to access surgery. A complete in vitro model mimicking the pulsatile upper extremity vasculature is in development and is expected to provide guidance in the future [9]. With continued improvements in predictive models utilizing clinically relevant and economically prudent imaging modalities, a truly individualized preoperative vascular access predictive tool may be realized in future.

\section{VENOUS STENOSIS- ROLE OF NEOINTIMAL HYPERPLASIA}

Vascular access dysfunction may be seen from the time of access creation to its abandonment. A significant proportion of AVF created still fail to mature with rates varying from $30 \%$ to $60 \%$ even with some recent improvements [10-13]. Such high primary failure has consequences in the form of catheter dependence, limited available access sites, patient and or health care provider fatigue.

Vascular remodeling is initiated in both feeding artery and draining vein once the anastomosis is created between them [14]. This results in either a healthy outward remodeling or an unhealthy inward remodeling. The unhealthy inward remodeling leads to compromise of access lumen identified as stenosis on imaging modalities. The most important factor for early AVF and AVG dysfunction is venous neointimal hyperplasia (NIH) $[15,16]$. The histopathology of NIH at the vein to graft anastomosis has been eloquently described by Roy-Chaudhury [16]. Venous NIH is characterized by presence of actin positive smooth muscle cells along with extracellular matrix, markers of oxidative stress and growth factors [17]. Composition of early and late venous stenosis in AVF is similar to that of AVG; unfortunately the intimal substrate is abnormal showing changes of intimal hyperplasia even before a fistula is created as demonstrated by Lee et al. [3, 15]. Other factors which may contribute to the development and propagation of $\mathrm{NIH}$ include oxidative stress and inflammatory mediators (Table 1). These processes lead to: (1) Activation, migration and proliferation of smooth muscle cells and myofibroblasts; (2) Formation of Neointimal Hyperplasia. Markers of endothelial dysfunction such as increased thickening of arterial intima, media and medial hypertrophy that result from these processes are found to affect the outcome of AVF [18-20]. With these known and possibly many unknown factors (Hemoxygenase 1, Nitrotyrosine) in play, a better understanding of the interaction between the flow dynamic and vascular adaptations are essential for developing successful therapy [21].

Table 1. Oxidative stress and inflammatory mediators.

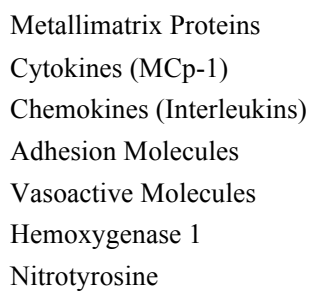

\section{TREATMENT OF VASCULAR ACCESS DYSFUNCTION}

The options for treating vascular access dysfunctions can broadly be divided into

1) Prevention and or suppression of NIH development.

2) Treatment of established neointimal hyperplasia

Developments in antiproliferative agents and modes of their delivery are very promising in addressing the preventive measures against NIH. Among treatment for established $\mathrm{NIH}$, percutaneous transluminal angioplasty (PTA) has been the mainstay along with increasing role of percutaneous transluminal endovascular stent placement (PTS). The following section will provide a brief description of recent developments in vascular access dysfunction.

\section{Pharmacotherapy in Dialysis Access}

Advances in understanding the pathogenesis and mediators of $\mathrm{NIH}$, has generated attempts to evaluate benefits of using commercially available antiproliferative and antithrombotic drugs in vascular access care. A recent review by Jackson et al., found only 13 randomized clinical trials investigating use of medications to improve vascular access patency in last 60 years [22]. Among these, antiplatelet agents are by far the most studied including Aspirin, Dipyridamole, Ticlopidine and Clopidrogel.

A randomized double blind control trial of Dipyridamole with Aspirin showed modest but significant increase in unassisted primary patency at one year ( $\mathrm{HR}=0.82$, CI 0.68 $0.98, \mathrm{p}=0.03$ ) without significant cumulative survival [23]. 
Among the three randomized clinical trials with clopidogrel, the recent study by Dialysis Access Consortium evaluated the thrombosis rates of AVF at 6 weeks post surgery in more than 800 patients randomized to receive either clopidogrel or placebo [13]. The study reported a reduction in arteriovenous fistula occlusion at 6 weeks (relative risk reduction $=0.63$ ) with no significant difference between the two groups on secondary outcome of fistula usability. However this study had a very high failure to mature rate even though all AVF were created at academic medical centers; this limited the ability to improvement in short term patency rates with use of antiplatelet agents. Meaningful clinical applications are yet to be ascertained.

The most interesting natural supplement product that generated interest in modifying the pathogenesis of NIH is "Fish Oil". The main ingredients eicosapentaenoic acid and docosahexaenoic acid have been shown to have antiproliferative, antioxidative effects that could affect neointimal hyperplasia $[24,25]$. In a canine model of vein graft arteriosclerosis, fish oil was found to inhibit intimal thickness [26]. In a small, single centered double blinded randomized trial by Schmitz et al., fish oil administration lead to a significantly higher primary patency rate at 1 year ( $75 \%$ to $14 \%$ ) among hemodialysis grafts [27]. These promising results lead to a recently reported multi-centered double blind randomized controlled trial, "Fish oil inhibition of stenosis in hemodialysis grafts study" (FISH study) that evaluated not only the patency rates of the access but also the cardiovascular outcomes in dialysis patients [28]. 201 chronic kidney disease stage 5 patients were randomized to receive 4 grams of deodorized fish oil or placebo 7 days after creation of AVG. At 12 months of follow-up, there was no significant difference in primary end point of graft thrombosis or revisions, but patients on fish oil supplementation had fewer thrombotic episodes, interventions and improved cardiovascular survival.

Thus, even though an effective pharmacotherapy still eludes us despite advanced knowledge about processes leading to vascular access dysfunction, additional approaches continue. Some of the drugs of interest for future include cilostazol. Cilostazol is a phosphodiesterase III inhibitor with antiplatelet and vascular smooth muscle cell proliferation inhibitor properties. Cilostazol was found to decrease restenosis rates in coronary artery angioplasty [29]. In another study, hemodialysis patients undergoing peripheral arterial angioplasty were enrolled to receive cilostazol along with standard therapy and compared with standard therapy alone [30]. Cilostazol was found to have a beneficial effect on restenosis and was an independent predictor of preventing restenosis $(\mathrm{HR}=0.50$, CI 0.26 to $0.87, \mathrm{P}=0.014$ ). Though no current studies have evaluated its effects on restenosis rates following angioplasty of dialysis access, future studies in this area may be beneficial.

\section{Antiproliferative Agents in Dialysis Access Dysfunction}

Modification of the venous endothelial response to arteriovenous fistula or graft creation appears to be the center stage for novel therapies. Drug eluting devices have been in development for over 10 years, mainly in the coronary artery disease. With the development and increased use of endovascular stent technology in coronary arteries, NIH was recognized to be a major factor affecting the long term outcomes. Antiproliferative agents were incorporated into the stent in an effort to prevent development of NIH. Sirolimus and its analogues Everolimus and Zatorolimus are actively being studied and some have entered clinical use via coronary endovascular stents [59]. The first in human study of using sirolimus eluting vascular wrap around graft vein anastomosis was recently reported by Paulson et al. [60]. Safety and efficacy of using sirolimus eluting wraps placed around the venous anastomosis was studied in 12 patients with 13 graft placements. This small study reported no perioperative drug related complications with systemic drug levels sub therapeutic for immunosuppresion and a primary unassisted patency rates at 12 and 24 months of $76 \%$ and $38 \%$. Although in its early stage, this promising results need to be explored in larger clinical trials.

Paclitaxel, a mitotic inhibitor developed by national cancer institute is a cancer chemotherapy medication used for lung, breast, ovarian, head and neck and Kaposi`s sarcoma. Paclitaxel coated drug eluting coronary stents have been widely studied along with sirolimus based devices. It was one of the four drugs found to inhibit human aortic smooth muscle proliferation but at concentrations much above much above those that could be achieved by systemic administration [61]. Drug delivery system, like antiproliferative agents is equally important in preventing neointimal hyperplasia. For hemodialysis access, drug delivery has to be local and prolonged over a period of time. The current delivery systems mainly include drug coated balloons and drug impregnated perivascular wraps [62].

Kohler et al. used paclitaxel coated vascular wraps at the venous anastomosis in an animal study [63]. Forty neutered male sheep were assigned to receive the vascular wraps at different drug concentration during the construction of arteriovenous grafts. Paclitaxel eluting wraps significantly reduced neointimal proliferation without affecting the wound healing or local injury to the vein.

Katsanos et al. reported a 6 month randomized prospective trial comparing paclitaxel coated angioplasty balloon to standard angioplasty balloon [64]. In this study, 40 patients were randomized into two groups of 20 each. One group received angioplasty using paclitaxel coated angioplasty balloon and the control group with standard angioplasty balloon. Though device success was only $45 \%$ in the paclitaxel group, procedure success was $100 \%$ in both groups with the use of high pressure balloons. At 6 months, paclitaxel group had significantly higher primary patency compared with standard group (70\% vs $25 \% \mathrm{p}<0.006)$. Though more robust studies with adequate power and long term patency rate are needed to confirm this advantage, it does demonstrate even short exposure time from a coated balloon angioplasty itself may be enough to improve the primary patency rate.

\section{Role of Brachytherapy to Treat NIH}

Early work at inhibiting vascular restenosis evaluated the effect of brachytherapy on the cellular response of vascular injury $[65,66]$. Radiation therapy to treat neo intimal hyperplasia was studied mainly in the context of coronary and peripheral arterial angioplasties with and without stent 
placement [67]. Though in the interim period, there was reasonable reduction in re-stenosis rate, long term benefits were lacking. Along with the advent of drug eluting stents and advancement of vascular medicine, use of radiation therapy for use in coronary and peripheral arterial disease went out of favor. Teratola et al. used brachytherapy in a dog model to induce reduction of neointimal hyperplasia in an arteriovenous graft [68]. Early clinical studies by Cohen et al. on use of external beam radiation in dialysis access in 31 patients showed minimal effect on venous stenosis [69]. The promising data from animal studies but mixed results from early human studies on use of radiation therapy to prevent venous stenosis led to Beta Radiation for ArterioVenous Graft Outflow Stenosis study (BRAVO 1) [70]. This pilot study to evaluate effect of brachytherapy on dysfunctional but patent AVG was conducted among 25 patients. Though brachytherapy was found to be safe and primary patency at 6 months was statistically significant ( $42 \%$ vs $0 \% \mathrm{p}=0.015$ ), secondary patency did not improve at 6 or 12 months. The subsequent larger randomized study (BRAVO 2) with a recruitment goal of 215 patients was discontinued for non patient safety reasons [71]. Lack of proven therapy to treat vascular access dysfunction demands continued search for a viable alternative and brachytherapy is still a contender.

\section{Percutaneous Transluminal Angioplasty (PTA) of Dysfunctional Arteriovenous Fistula or Grafts}

The current therapies employed to treat vascular access dysfunction have centered on ways and means of maintaining luminal patency. Since 1980`s when angiography was employed for evaluation of vascular access dysfunction, angioplasty has been the standard of care in maintaining luminal patency by treating venous stenosis [31, 32]. Over the course of 3 decades, this technique evolved from a hospital based inpatient setting to being an outpatient office based procedure enabled by advances in hardware utilized for these procedures.

The main aim of performing a percutaneous transluminal angioplasty of established venous stenosis has been to induce a controlled dissection of the vessel wall with the goal of increasing the luminal size and in so doing disrupt the neointimal hyperplasia by either compression and/or inducing micro fractures. KDOQI guidelines state that any stenosis $>50 \%$ in relation to a normal appearing adjacent venous segment in conjunction with clinical or physiological symptoms be treated with PTA or surgical revision [1]. A successful angioplasty has been defined as residual stenosis $<30 \%$ with acceptable resolution of clinical and physiological parameters used to detect the stenosis in AVG.

Compared to AVG, literature on PTA of AVF are limited in numbers but with reported technical success rates as high as $96.5 \% \quad(n=1561)$ [33]. In percutaneous transluminal angioplasty of AVF venous stenosis, $30 \%$ residual stenosis has not been found to be a significant factor in clinical outcomes [34]. In a retrospective cohort study of 65 consecutive patients with native AVF who underwent angioplasty, there was no significant difference in long term patency between 17 lesions with greater than $30 \%$ residual stenosis and the remaining lesions with less than $30 \%$ stenosis. The observation that stenotic segment length was more important than the degree of stenosis for long term outcomes is important. The resistance to flow is not just a function of the cross sectional area but the length of the lesion as well. The patency rates for PTA of fistula have varied depending on the type and age of the fistula. The primary patency rates have been anywhere from $55 \%-77 \%$ at 6 months and $26 \%-51 \%$ at 12 months. The secondary patency rates are more promising at $80 \%$ to $90 \%$ at both 6 and 12 months [34-37]. With lack of well designed outcome studies, the efficacy of PTA in treating venous stenosis i.e. $\mathrm{NIH}$ in arteriovenous fistula is debatable, particularly if the inter-procedure interval shortens to several months.

Once an access is occluded, optimal methods available include surgical thrombectomy or percutaneous endovascular techniques utilitizing mechanical or chemical thrombolytics and or thromboaspiration. A recent meta-analysis by Kuhan et al. reported no randomized studies comparing surgical vs endovascular techniques to treat thrombosis in native fistula [38]. Only 6 randomized clinical trials evaluated surgical technique in comparison with endovascular techniques in prosthetic grafts. Technical success, need for access line, patency at 30 days and one year were similar between the two groups and assisted patency at 1 year was better for surgery. The included studies were conducted mostly before 2000 and some of the findings were contradictory to an earlier meta-analysis by Green et al. in 2002 [39]. At the present time, endovascular treatment of occluded prosthetic grafts is the preferred method based on evidence from historical studies. Advancement in endovascular balloon, endovascular stents and thrombectomy devices probably have made an impact but strong statistical evidence favoring endovascular techniques is still lacking. These inconsistencies in results could be attributable to some degree on variation in definition of endpoints. North American Vascular Access Consortium has proposed working and standard vascular access definitions to bring common ground as has the Society for Vascular Surgery [40, 41]. Future researchers are strongly encouraged to use these standard definitions to bring about consistency in vascular access literature.

\section{Advances in Imaging Modality: Ultrasound Guided Percutaneous Transluminal Angioplasty}

The gold standard imaging modality for performing percutaneous transluminal angioplasty of the blood vessels has been fluoroscopy and digital subtraction angiography. Some of the drawbacks of this modality are: 1- Exposure to radiation; 2- Exposure to iodinated contrast agents; 3Fluoroscopic imaging hardware. Advances in ultrasonography have provided an alternate option for performing percutaneous transluminal angioplasty (PTA). In 1996, Wittenberg et al. described the technical aspects of using color coded duplex sonography to guide peripheral interventions in dialysis shunts [42]. Duplex guidance has been used for interventions in peripheral arteries and even internal carotid arteries [43-45]. In 2007, the group from Maimonides Medical Center in Brooklyn, NY reported performance of angioplasty on 10 dialysis access (9 fistulae and $1 \mathrm{graft}$ ) including placement of an endovascular stent for elastic recoil [46]. Two years later, the same authors reported data on 25 patients with 32 office based duplex guided 
angioplasties of autologous fistulae [47]. 27 of the 32 procedures were performed on failure to mature fistula. All procedures were completed without the need for fluoroscopic guidance with only two patients experiencing significant complications. They also reported a 4.32 times more revenue from using the duplex guidance in comparison with hospital based fluoroscopic guidance. As they used only the professional component of the hospital based fluoroscopic procedures for this comparison, the data on real cost savings in comparison with office based fluoroscopic procedure is lacking.

In 2010, Fox et al. reported the outcomes in 223 office based duplex guided dialysis access angioplasty procedures [48]. This study excluded patients with possible central venous stenosis and measured changes in volume flow together with changes in luminal diameter. With the use of ultrasound guided local infiltration of lidocaine, conscious sedation was avoided and hence the associated need for trained personnel, sedation risk and post procedure recovery issues. $98 \%$ of procedures $(n=219)$ achieved technical success with $9 \%$ of the patients $(n=21)$ developing minor complications. Although this study reported high technical success along with low complication rates, it lacked predefined clinical end points i.e. long term patency rates.

Recently, Wakabayashi et al. reported from Japan results from 4869 ultrasound guided percutaneous transluminal angioplasties in more than one thousand patients over a 7 year period [49]. Along with peripheral vessels, they used a microconvex transducer probe to visualize subclavian and brachiocephalic veins through the intercostals space. Unlike prior studies thrombo-aspiration was also performed under ultrasound guidance for thrombosed accesses. Overall technical success was achieved in 97\% (4731 out of 4869) with equivalent success in thrombosed procedures (443 out of 455). Though fluoroscopic guidance was used for bailout during the earlier phase of the study period, procedures were done completely under ultrasound guidance last two years of the study period. The overall one month patency rate was $94 \%$ with thrombosed cases also having a patency rate of $91 \%$ at 30 days. Major complications requiring surgical interventions were very small $(\mathrm{n}=12)$.

These early studies utilizing ultrasound guidance for PTA have reported the technical and safety details under various clinical scenarios including thrombosed access. The advantages of ultrasound guidance include lack of radiation exposure for both patient and healthcare associates, no requirement of the more expensive fluoroscopic hardware, less digital footprint and possible development in the future of performing the procedures in the dialysis chair. There is a perceived economic advantage of this guidance compared with hospital based fluoroscopic studies but true cost comparison with office based fluoroscopic studies is still warranted. The need for a trained vascular technologist to be part of the procedure is a disadvantage and might mitigate the some of the positives associated with this guidance. In addition, the inability to visualize central venous system may be a limitation for this guidance and makes the case for long term patency studies in comparison with fluoroscopic guidance to be done to assess its impact. Though promising, studies evaluating ultrasound guided percutaneous procedure outcomes in relation to type and position of the dialysis access also are sorely warranted before this can become the modality of choice.

\section{Genetics in Vascular Access Care}

If endovascular changes like neo-intimal hyperplasia can be avoided or altered, then subsequent luminal narrowing and access dysfunction can be minimized. This logical approach has lead to many attempts at modifying or mitigating the endovascular changes.

Genetic composition is increasingly being recognized to play a role in many aspects of medicine. In many studies graft and fistula failure has been linked to genetic polymorphisms [50]. Polymorphisms of methylenetetrahydrofolate reductase (MTHFR), Hemeoxygenase 1, factor $\mathrm{V}$, transforming growth factor_1 and klotho and more recently have independently linked SNP rs6019 polymorphisms of factor $\mathrm{V}$, a prothrombotic compound with graft failure [50-57]. Genetic modification not only involves identification of genes involved but also developing an optimal, clinically relevant method for delivery. In a recent animal model, Globerman et al. attempted to use plasmid based vascular gene delivery system [58]. Plasmids encoding for endothelial nitric oxide genes were instilled into the blood vessels at the time or after arteriovenous fistula creation in a rat AVF model. Transgene expression was confined to the venous limb of the fistula with no adverse tissue reaction and with sustained production of nitric oxide. Though it is at an early stage, gene therapy is an exciting avenue for the future.

\section{SUMMARY}

Vascular access continues to be the weakest link in the care of end stage renal disease patients. Advances in predictive medicine to identify an optimal access along with judicious use for antiproliferative therapy to minimize the burden of neointimal hyperplasia and its downstream complications may provide us with an elusive ideal vascular access. Further studies utilizing a combination of measures might be needed to evaluate the additive effects of different therapeutic modalities.

\section{CONFLICT OF INTEREST}

The authors confirm that this article content has no conflict of interest.

\section{ACKNOWLEDGEMENTS}

Declared none.

\section{REFERENCES}

[1] Navuluri R, Regalado S. The KDOQI 2006 Vascular access update and fistula first program synopsis. Semin Intervent Rad 2009; 26(2): 122-4

[2] Konner K. History of vascular access for haemodialysis. Nephrol Dial Transplant 2005; 20(12): 2629-35.

[3] Lee T, Chauhan V, Krishnamoorthy M, et al. Severe venous neointimal hyperplasia prior to dialysis access surgery. Nephrol Dial Transplant 2011; 26(7): 2264-70.

[4] Ferring M, Claridge M, Smith SA, Wilmink T. Routine preoperative vascular ultrasound improves patency and use of 
arteriovenous fistulas for hemodialysis: a randomized trial. Clin J Am Soc Nephrol 2010; 5(12): 2236-44.

[5] Ferring M, Henderson J, Wilmink A, Smith S. Vascular ultrasound for the pre-operative evaluation prior to arteriovenous fistula formation for haemodialysis: review of the evidence. Nephrol Dial Transplant 2008; 23(6): 1809-15.

[6] Peterson WJ, Barker J, Allon M. Disparities in fistula maturation persist despite preoperative vascular mapping. Clin J Am Soc Nephrol 2008; 3(2): 437-41.

[7] Bode AS, Huberts W, Bosboom EM, et al. Patient-specific computational modeling of upper extremity arteriovenous fistula creation: its feasibility to support clinical decision-making. PloS one 2012; 7(4): e34491.

[8] Merkx MA, Bode AS, Huberts W, et al. Assisting vascular access surgery planning for hemodialysis by using MR, image segmentation techniques, and computer simulations. Med Biol Eng Comput 2013; 51(8): 879-89.

[9] Chandra A, Mix D, Varble N. Hemodynamic study of arteriovenous fistulas for hemodialysis access. Vascular 2013; 21(1): 54-62.

[10] Schinstock CA, Albright RC, Williams AW, et al. Outcomes of arteriovenous fistula creation after the fistula first initiative. Clin J Am Soc Nephrol 2011; 6(8): 1996-2002.

[11] Huijbregts HJ, Bots ML, Wittens CH, Schrama YC, Moll FL, Blankestijn PJ. Hemodialysis arteriovenous fistula patency revisited: results of a prospective, multicenter initiative. Clin J Am Soc Nephrol 2008; 3(3): 714-9.

[12] Patel ST, Hughes J, Mills JL, Sr. Failure of arteriovenous fistula maturation: an unintended consequence of exceeding dialysis outcome quality initiative guidelines for hemodialysis access. J Vasc Surg 2003; 38(3): 439-45; discussion 45.

[13] Dember LM, Beck GJ, Allon M, et al. Effect of clopidogrel on early failure of arteriovenous fistulas for hemodialysis: a randomized controlled trial. J Am Med Assoc 2008; 299(18): 216471.

[14] Dammers R, Tordoir JH, Kooman JP, et al. The effect of flow changes on the arterial system proximal to an arteriovenous fistula for hemodialysis. Ultrasound Med Biol 2005; 31(10): 1327-33.

[15] Roy-Chaudhury P, Arend L, Zhang J, et al. Neointimal hyperplasia in early arteriovenous fistula failure. Am J Kidney Dis 2007; 50(5): 782-90.

[16] Roy-Chaudhury P, Kelly BS, Miller MA, et al. Venous neointimal hyperplasia in polytetrafluoroethylene dialysis grafts. Kidney Int 2001; 59(6): 2325-34

[17] Weiss MF, Scivittaro V, Anderson JM. Oxidative stress and increased expression of growth factors in lesions of failed hemodialysis access. Am J Kidney Dis 2001; 37(5): 970-80.

[18] Kim YO, Choi YJ, Kim JI, et al. The impact of intima-media thickness of radial artery on early failure of radiocephalic arteriovenous fistula in hemodialysis patients. J Korean Med Sci 2006; 21(2): 284-9.

[19] Feinfeld DA, Batista R, Mir R, Babich D. Changes in venous histology in chronic hemodialysis patients. Am J Kidney Dis 1999; 34(4): 702-5.

[20] Juncos JP, Grande JP, Kang L, et al. MCP-1 contributes to arteriovenous fistula failure. J Am Soc Nephrol 2011; 22(1): 43-8.

[21] Kang L, Yamada S, Hernandez MC, et al. Regional and systemic hemodynamic responses following the creation of a murine arteriovenous fistula. Am J Physiol Renal Physiol 2011; 301(4): F845-51.

[22] Jackson AJ, Coats P, Kingsmore DB. Pharmacotherapy to improve outcomes in vascular access surgery: a review of current treatment strategies. Nephrol Dial Transplant 2012; 27(5): 2005-16.

[23] Dixon BS, Beck GJ, Vazquez MA, et al. Effect of dipyridamole plus aspirin on hemodialysis graft patency. N Eng J Med 2009; 360(21): 2191-201.

[24] Lok CE, Allon M, Donnelly S, et al. Design of the fish oil inhibition of stenosis in hemodialysis grafts (FISH) study. Clin Trials 2007; 4(4): 357-67.

[25] Yevzlin AS, Chan MR, Becker YT, Roy-Chaudhury P, Lee T, Becker BN. "Venopathy" at work: recasting neointimal hyperplasia in a new light. Transl Res 2010; 156(4): 216-25.

[26] Sarris GE, Fann JI, Sokoloff MH, et al. Mechanisms responsible for inhibition of vein-graft arteriosclerosis by fish oil. Circulation 1989; 80(3 Pt 1): I109-23.
[27] Schmitz PG, McCloud LK, Reikes ST, Leonard CL, Gellens ME. Prophylaxis of hemodialysis graft thrombosis with fish oil: doubleblind, randomized, prospective trial. J Am Soc Nephrol 2002;13(1):184-90.

[28] Lok CE, Moist L, Hemmelgarn BR, et al. Effect of fish oil supplementation on graft patency and cardiovascular events among patients with new synthetic arteriovenous hemodialysis grafts: a randomized controlled trial. J Am Med Assoc 2012; 307(17): 1809. 16

[29] Tsuchikane E, Fukuhara A, Kobayashi T, et al. Impact of cilostazol on restenosis after percutaneous coronary balloon angioplasty. Circulation 1999; 100(1): 21-6.

[30] Ishii H, Kumada Y, Toriyama T, et al. Cilostazol improves longterm patency after percutaneous transluminal angioplasty in hemodialysis patients with peripheral artery disease. J Am Soc Nephrol 2008; 3(4): 1034-40.

[31] Glanz S, Bashist B, Gordon DH, Butt K, Adamsons R. Angiography of upper extremity access fistulas for dialysis. Radiology 1982; 143(1): 45-52.

[32] Gordon DH, Glanz S, Butt KM, Adamsons RJ, Koenig MA Treatment of stenotic lesions in dialysis access fistulas and shunts by transluminal angioplasty. Radiology 1982; 143(1): 53-8.

[33] Beathard GA, Litchfield T. Effectiveness and safety of dialysis vascular access procedures performed by interventional nephrologists. Kidney Int 2004; 66(4): 1622-32.

[34] Clark TW, Hirsch DA, Jindal KJ, Veugelers PJ, LeBlanc J. Outcome and prognostic factors of restenosis after percutaneous treatment of native hemodialysis fistulas. J Vasc Interv Radiol 2002; 13(1): 51-9.

[35] Manninen HI, Kaukanen ET, Ikaheimo R, et al. Brachial arterial access: endovascular treatment of failing Brescia-Cimino hemodialysis fistulas--initial success and long-term results. Radiology 2001; 218(3): 711-8.

[36] Rajan DK, Bunston S, Misra S, Pinto R, Lok CE. Dysfunctional autogenous hemodialysis fistulas: outcomes after angioplasty--are there clinical predictors of patency? Radiology 2004; 232(2): 50815 .

[37] Turmel-Rodrigues L, Pengloan J, Baudin S, et al. Treatment of stenosis and thrombosis in haemodialysis fistulas and grafts by interventional radiology. Nephrol Dial Transplant 2000; 15(12): 2029-36

[38] Kuhan G, Antoniou GA, Nikam M, et al. A meta-analysis of randomized trials comparing surgery versus endovascular therapy for thrombosed arteriovenous fistulas and grafts in hemodialysis. Cardiovasc Intervent Radiol 2013

[39] Green LD, Lee DS, Kucey DS. A meta-analysis comparing surgical thrombectomy, mechanical thrombectomy, and pharmacomechanical thrombolysis for thrombosed dialysis grafts. J Vasc Surg 2002; 36(5): 939-45.

[40] Lee T, Mokrzycki M, Moist L, Maya I, Vazquez M, Lok CE. Standardized definitions for hemodialysis vascular access. Semin Diagn Pathol 2011; 24(5): 515-24.

[41] Sidawy AN, Spergel LM, Besarab A, et al. The society for vascular surgery: clinical practice guidelines for the surgical placement and maintenance of arteriovenous hemodialysis access. J Vasc Surg 2008; 48(Suppl 5): S2-25.

[42] Wittenberg G, Kellner M, Kenn W, et al. [Initial experiences with dilatation of dialysis shunts with color-coded duplex ultrasonography monitoring]. RoFo 1996; 164(1): 38-41.

[43] Ascher E, Marks NA, Hingorani AP, Schutzer RW, Nahata S. Duplex-guided balloon angioplasty and subintimal dissection of infrapopliteal arteries: early results with a new approach to avoid radiation exposure and contrast material. J Vasc Surg 2005; 42(6): 1114-21.

[44] Ascher E, Marks NA, Schutzer RW, Hingorani AP. Duplex-guided balloon angioplasty and stenting for femoropopliteal arterial occlusive disease: an alternative in patients with renal insufficiency. J Vasc Surg 2005; 42(6): 1108-13.

[45] Ascher E, Marks NA, Schutzer RW, Hingorani AP. Duplexassisted internal carotid artery balloon angioplasty and stent placement: a novel approach to minimize or eliminate the use of contrast material. J Vasc Surg 2005; 41(3): 409-15.

[46] Marks N, Ascher E, Hingorani AP. Duplex-guided repair of failing or nonmaturing arterio-venous access for hemodialysis. Perspect Vasc Surg Endovasc Ther 2007; 19(1): 50-5. 
[47] Ascher E, Hingorani A, Marks N. Duplex-guided balloon angioplasty of failing or nonmaturing arterio-venous fistulae for hemodialysis: a new office-based procedure. J Vasc Surg 2009; 50(3): 594-9.

[48] Fox D, Amador F, Clarke D, et al. Duplex guided dialysis access interventions can be performed safely in the office setting: techniques and early results. Eur J Vasc Endo Vasc 2011; 42(6): 833-41.

[49] Wakabayashi M, Hanada S, Nakano H, Wakabayashi T, Ultrasound-guided endovascular treatment for vascular access malfunction: results in 4896 cases. J Vasc Access 2013; 14(3): 22530.

[50] Girndt M, Heine GH, Ulrich C, Kohler H. Gene polymorphism association studies in dialysis: vascular access. Semin Dial 2007; 20(1): 63-7.

[51] Allon M, Zhang L, Maya ID, Bray MS, Fernandez JR. Association of factor $\mathrm{V}$ gene polymorphism with arteriovenous graft failure. Am J Kidney Dis 2012; 59(5): 682-8.

[52] Fukasawa M, Matsushita K, Kamiyama M, et al. The methylentetrahydrofolate reductase $\mathrm{C} 677 \mathrm{~T}$ point mutation is a risk factor for vascular access thrombosis in hemodialysis patients. Am J Kidney Dis 2003; 41(3): 637-42.

[53] Heine GH, Ulrich C, Sester U, Sester M, Kohler H, Girndt M. Transforming growth factor betal genotype polymorphisms determine AV fistula patency in hemodialysis patients. Kidney Int 2003; 64(3): 1101-7.

[54] Kim Y, Jeong SJ, Lee HS, et al. Polymorphism in the promoter region of the klotho gene (G-395A) is associated with early dysfunction in vascular access in hemodialysis patients. Korean J Intern Med 2008; 23(4): 201-7.

[55] Knoll GA, Wells PS, Young D, et al. Thrombophilia and the risk for hemodialysis vascular access thrombosis. J Am Soc Nephrol 2005; 16(4): 1108-14.

[56] Lazo-Langner A, Knoll GA, Wells PS, Carson N, Rodger MA. The risk of dialysis access thrombosis is related to the transforming growth factor-betal production haplotype and is modified by polymorphisms in the plasminogen activator inhibitor-type 1 gene. Blood 2006; 108(13): 4052-8.

[57] Lin CC, Yang WC, Lin SJ, et al. Length polymorphism in heme oxygenase- 1 is associated with arteriovenous fistula patency in hemodialysis patients. Kidney Int 2006; 69(1): 165-72.

[58] Globerman AS, Chaouat M, Shlomai Z, Galun E, Zeira E, Zamir G. Efficient transgene expression from naked DNA delivered into an arterio-venous fistula model for kidney dialysis. J Gene Med 2011; 13(11): 611-21.

[59] Saia F, Piovaccari G, Manari A, et al. Clinical outcomes for sirolimus-eluting stents and polymer-coated paclitaxel-eluting stents in daily practice: results from a large multicenter registry. J Am Coll Cardiol 2006; 48(7): 1312-8.

[60] Paulson WD, Kipshidze N, Kipiani K, et al. Safety and efficacy of local periadventitial delivery of sirolimus for improving hemodialysis graft patency: first human experience with a sirolimus-eluting collagen membrane (Coll-R). Nephrol Dial Transplant 2012; 27(3): 1219-24.

[61] Masaki T, Kamerath CD, Kim SJ, Leypoldt JK, Mohammad SF, Cheung AK. In vitro pharmacological inhibition of human vascular smooth muscle cell proliferation for the prevention of hemodialysis vascular access stenosis. Blood Purif 2004; 22(3): 307-12.

[62] Melhem M, Kelly B, Zhang J, et al. Development of a local perivascular paclitaxel delivery system for hemodialysis vascular access dysfunction: polymer preparation and in vitro activity. Blood Purif 2006; 24(3): 289-98.

[63] Kohler TR, Toleikis PM, Gravett DM, Avelar RL. Inhibition of neointimal hyperplasia in a sheep model of dialysis access failure with the bioabsorbable Vascular Wrap paclitaxel-eluting mesh. J Vasc Surg 2007; 45(5): 1029-37; discussion 37-8.

[64] Katsanos K, Karnabatidis D, Kitrou P, Spiliopoulos S, Christeas N, Siablis D. Paclitaxel-coated balloon angioplasty $v s$ plain balloon dilation for the treatment of failing dialysis access: 6-month interim results from a prospective randomized controlled trial. J Endovasc Ther 2012; 19(2): 263-72.

[65] Rubin P, Williams JP, Riggs PN, et al. Cellular and molecular mechanisms of radiation inhibition of restenosis. Part I: role of the macrophage and platelet-derived growth factor. Int J Radiat Oncol 1998; 40(4): 929-41.

[66] Fareh J, Martel R, Kermani P, Leclerc G. Cellular effects of betaparticle delivery on vascular smooth muscle cells and endothelial cells: a dose-response study. Circulation 1999; 99(11): 1477-84.

[67] Ahmed S, Roy-Chaudhury P. Radiation therapy for dialysis access stenosis: unfulfilled promise or false expectations. Semin Dial 2012; 25(4): 464-9.

[68] Trerotola SO, Carmody TJ, Timmerman RD, et al. Brachytherapy for the prevention of stenosis in a canine hemodialysis graft model: preliminary observations. Radiology 1999; 212(3): 748-54.

[69] Cohen GS, Freeman H, Ringold MA, et al. External beam irradiation as an adjunctive treatment in failing dialysis shunts. J Vasc Interv Radiol 2000; 11(3): 321-6.

[70] Misra S, Bonan R, Pflederer T, Roy-Chaudhury P. BRAVO I: a pilot study of vascular brachytherapy in polytetrafluoroethylene dialysis access grafts. Kidney Int 2006; 70(11): 2006-13.

[71] Roy-Chaudhury P, Arnold P, Seigel J, Misra S. From basic biology to randomized clinical trial: The beta radiation for arteriovenous graft outflow stenosis (BRAVO II). Semin Dial 2013; 26(2): 22732 .

(C) Kumbar et al.; Licensee Bentham Open.

This is an open access article licensed under the terms of the Creative Commons Attribution Non-Commercial License (http://creativecommons.org/licenses/by-nc/3.0/) which permits unrestricted, non-commercial use, distribution and reproduction in any medium, provided the work is properly cited. 